\title{
STRATEGI KOMUNIKASI VOLUNTARY COUNSELING TEST (VCT) TERHADAP ORANG DENGAN HIV/AIDS (ODHA) DI RUMAH SAKIT UMUM DR. SAIFUL ANWAR MALANG (RSSA)
}

\author{
Kresna Abdi Parela \\ IKIP Budi Utomo Malang \\ Jalan Citandui 46 Malang
}

\begin{abstract}
Communication Strategy Voluntary Counseling Test ( VCT ) Living with HIV / AIDS ( PLWHA ) General Hospital Dr. Saiful Anwar ( RSSA ) HIV / AIDS is still one of the dreaded disease by a large part of society, because they still consider HIV / AIDS as a deadly disease, there is no cure and the disease is a curse. This is caused due to an incorrect myths about HIV/AIDS. Due to the myth , making people living with HIV / AIDS ( PLWHA) are stigmatized and discrimination. Stigma and discrimination are two things that are often experienced by people living with HIV. Because of the stigma and discrimination that people living with HIV be afraid, afraid to open up for fear of being shut excluded so that people living with HIV and people living with HIV closure that makes HIV / AIDS is difficult to detect its spread. To overcome these problems, one of which is through Voluntary Counseling Test (VCT). VCT counseling is an activity that provides psychological support, information and knowledge of HIV / AIDS, prevent the transmission of HIV, promote responsible behavior change, treatment and ensure solving various problems associated with HIV / VCT AIDS.Ada in two stages, namely the stage of Pre- Test and Post- Tests .

In the Pre- test counseling is done stage by providing information about HIV / AIDS, prevention, transmission and window period. Pre- test counseling provides knowledge about the benefits of HIV testing, testing for decision making, and planning for issues facing HIV. After HIV Testing and Counseling Pre PLWHA PLWHA undergo the HIV test will undergo stages of post counseling where PLHIV will be conditioned to accept the results of the HIV test, get information about what to do if the results of his HIV test is positive or negative, and most importantly so that people living with HIV do not become stress, depression and despair. VCT is run by counselors who are trained and experienced in this study bidangnya.Pada researchers conducted a study using qualitative methods to the three counselors that have been set using purposive sampling method and data captured through interviews and counseling in VCT observasi.Ketika Pre Test and post- test, the counselor needs a communications strategy that will be used to affect people living with HIV in order to receive the message delivered by the counselor and the main thing is to change the behavior of people living with HIV. Based on the results of research conducted by the researchers of the communication strategy VCT Pre Test and Post-Test in Dr. Saiful Anwar Hospital Malang against people living with HIV, it was found that the result is a persuasive communication strategies used by counselors when doing koneling to PLWHA HIV Testing Pre and Communication, Information andEducation (CIE) is a communication strategy that is used by counselors when counseling Post- test counseling is done by the counselor was tailored to what the existing problems in people living with HIV with the ultimate goal, namely a change in the behavior of people living with HIV.
\end{abstract}

Keywords :Communication Strategies Voluntary Counseling Test ( VCT ), people living with HIV / AIDS ( PLWHA)

HIV/AIDS merupakan penyakit yang belum ditemukan obatnya hingga saat ini dan mendapatkan stigma negatif di mata masyarakat. Stigma negati terhadap HIV / AIDS ini juga menimbulkan diskriminasi kepada penderitanya atau yang disebut dengan ODHA (Orang Dengan HIV/AIDS). Diskriminasi yang terjadi kepada ODHA, mengakibatkan ODHA menjadi pribadi yang tertutup, minder ,serta mengucilkan diri dari pergaulan masyarakat di sekitarnya. Hal inilah yang menjadi salah satu penyebab sulitnya mendeteksi penyebaran HIV/ AIDS di masyarakat.

Oleh karena itu banyak Rumah Sakit dan Puskesmas yang membuka Klinik Voluntary Counseling and Testing (VCT) yang melayani para penderita HIV/AIDS secara sukarela. VCT adalah kegiatan konseling yang menyediakan dukungan psikologis, informasi dan pengetahuan tentang HIV/AIDS, mencegah penularan HIV, mempromosikan perubahan perilaku yang bertanggung jawab, pengobatan 
ARV dan memastikan pemecahan berbagai masalah terkait HIV / AIDS. Konseling pada VCT yang dilakukan secara sukarela merupakan salah satu strategi kesehatan masyarakat sebagai pintu masuk ke seluruh layanan kesehatan HIV dan AIDS yang berkelanjutan. Program VCT dapat dilakukan berdasarkan kebutuhan pasien dengan memberikan layanan dini dan memadai baik kepada mereka dengan HIV positif dan negatif Layanan ini termasuk pencegahan primer melalui Komunikasi, Informasi dan Edukasi (KIE) seperti pemahaman HIV, pencegahan penularan dari ibu ke anak Prevention of Mother To Child Transmission (PMCT) dan akses terapi infeksi oportunistik seperti tuberkulosis (TBC) dan infeksi menular seksual (kpa.provsu.og).

Melalui VCT, diharapkan pasien mau membuka diri dan melakukan Tes HIV, sehingga diketahui apakah pasien tersebut positif tertular HIV/AIDS atau masih negatif. Untuk itulah diperlukan strategi komunikasi yang tepat dan terencana oleh konselor ketika melakukan konseling kepada pasien. Karena dengan strategi yang tepat dan terencana, maka konselor bisa mempengaruhi dan mengubah persepsi pasien tentang HIV/AIDS. Penelitian ini dilakukan di Rumah Sakit Umum Dr. Saiful anwar Malang (RSSA) terhadap empat konselor, yaitu konselor psikolog, konselor perawat, konselor Manajer kasus (MK) dan konselor kelompok dukungan sebaya (KDS) dengan metode wawancara tersrtuktur dan observasi tidak terstruktur untuk untuk menganalisis Strategi Komunikasi VCT HIV/ AIDS terhadap ODHA pra tes, pasca tes dan strategi komunikasi VCT yang disesuaikan dengan kebutuhan ODHA.

\section{METODE}

\section{Paradigma, Pendekatan dan Jenis Penelitian}

Penelitian ini menggunakan pendekatan kualitatif Studi Kasus dengan paradigma konstruktivisme yang pada intinya menganggap manusia bertindak sebagai agen yang mengkonstruksi realitas sosial baik itu melalui pemberian makna maupun pemahaman perilaku di kalangan mereka sendiri.Sedangkan jenis penelitiannya adalah penelitian deskriptif, yaitu penelitian yang berusaha mendeskripsikan dan menginterpretasikan sesuatu, misalnya kondisi atau hubungan yang ada, pendapat yang berkembang, proses yang sedang berlangsung, akibat atau efek yang terjadi, atau tentang kecendrungan yang tengah berlangsung.

\section{Subyek Penelitian}

Subjek dalam penelitian ini adalah Konselor Voluntary Counseling Test (VCT), seperti Psikolog,Perawat, dan Manajer Kasus (MK) yang akan diambil datanya melalui wawancara dan observasi serta telah ditetapkan menggunakan Metode Purposive Sampling, dimana subyek yang akan diteliti telah dipilih dan ditetapkan sesuai karakteristik penelitian. Karakteristik tersebut adalah :

1. Mengerti dan memahami banyak hal yang berkaitan dengan HIV / AIDS

2. Berinteraksi langsung dan intens dengan ODHA

3. Memiliki pengalaman melakukan konseling dengan ODHA

4. Pernah mengikuti seminar dan pelatihan tentang konseling

\section{Teknik Pengumpulan Data}

a. Wawancara. Metode wawancara yang digunakan dalam penelitian ini adalah wawancara terarah (Guided Interview) dimana peneliti menanyakan hal-hal yang sudah dipersiapkan sebelumnya kepada para konselor VCT (Perawat,Psikolog, dan Konselor MK) di Rumah Sakit Saiful Anwar (RSSA) di Kota Malang.

b. Observasi Non Partisipan, dimana peneliti datang ke tempat subyek penelitian yang diteliti, tetapi tidak ikut terlibat dalam kegiatan yang dilakukan subyek penelitan. Peneliti hanya sebatas mengamati dan menganalisis

\section{Teknik Analisa Data}

Analisis data pada penelitian ini menggunakan teknik analisis data Model Miles and Huberman, yaitu :

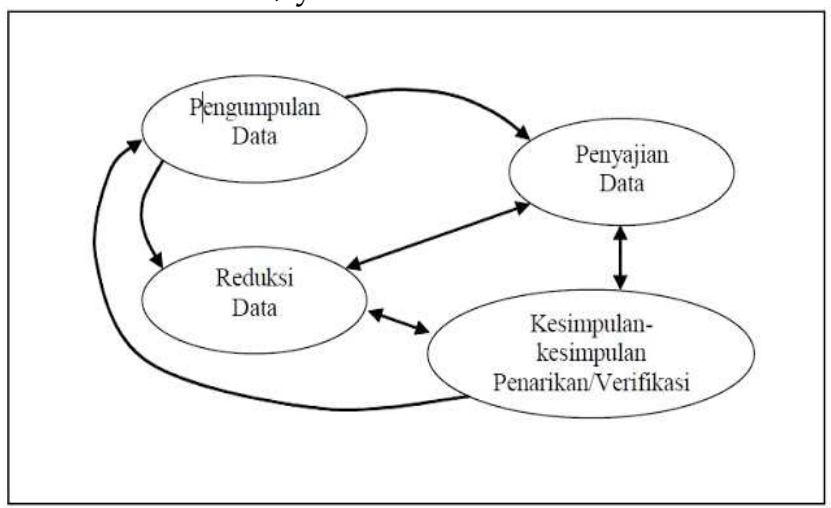

Gambar 1. Komponen-komponen Analisis Data: Model Interaktif 


\section{Uji Keabsahan Data}

Ada Beberapa langkah dalam menguji validitas dan Kredibilitas data dalam penelitian (Sugiyono, 2012) :

\section{Uji kredibilitas}

a. Triangulasi Teknik

Triangulasi teknik dilakukan dengan cara mengecek data kepada sumber yang sama dengan teknik yang berbeda. Misalnya data diperoleh dengan wawancara, lalu dicek dengan observasi.

\section{HASIL DAN PEMBAHASAN}

Strategi komunikasi adalah bagian penting dari proses konseling yang dilakukan oleh Konselor kepada pasien HIV/AIDS baik positif maupun negative Melalui strategi komunikasi konselor berusaha mempengaruhi pasien agar mau menuruti apa yang disarankan oleh konselor, seperti melakukan Tes HIV, rutin melakukan pengobatan, meninggalkan kegiatan yang beresiko mengakibatkan penularan dan penyebaran HIV/ AIDS serta yang utama adalah memberikan banyak informasi dan meluruskan mitos yang salah tentang HIV/AIDS kepada pasien.

Ada empat konselor dalam Voluntary Counseling Test (VCT), yaitu dua konselor dengan latar belakang sebagai seorang psikolog dan perawat dan satu konselor yang merupakan seorang aktivis dari Ikatan Gay Malang (IGAMA). Mereka bertiga memberikan konseling kepada pasien dengan HIV positif / negatif atau yang biasa disebut ODHA di Rumah Sakit Saiful Anwar Malang (RSSA). Serta seorang konselor dari Kelompok Dukungan Sebaya (KDS) yang memberikan konseling secara tidak formal kepada pasien. Keempatnya memiliki tujuan yang sama dalam melakukan konseling kepada pasien, hanya ada sedikit perbedaan. Konselor VCT dari latar belakang keilmuan psikolog melakukan pendekatan secara personal dan menggunakan pengalamannya sebagai seorang konselor ketika memberikan penjelasan kepada pasien. Keahlian konselor sebagai seorang psikolog juga digunakan ketika melakukan konseling, kemudian konselor psikolog terkadang menggunakan metode koersif kepada pasien yang bandel. Dalam arti sulit untuk mengubah perilaku berisikonya dan melakukan pengobatan secara rutin walaupun telah diberi pemahaman secara berulang - ulang.
Konselor dengan latar belakang perawat melakukan konseling juga dengan menggunakan pendekatan personal dan menggunakan pengalamannya sebagai seorang konselor untuk mempengaruhi pasien.Konselor perawat lebih sabar dalam memberikan konseling dengan menganggap pasien sebagai teman bahkan sebagai saudara. Sedangkan konselor Manajer Kasus (MK) melakukan konseling secara tidak formal dan melakukan pendekatan secara personal kepada pasien, kedekatan secara personal itu ditunjukkan dengan adanya konseling yang bisa berlangsung di rumah pasien atau melalui telepon san SMS. Konselor yang terakhir adalah konselor dari Kelompok Dukungan Sebaya (KDS), yang juga seorang ODHA dan memeberikan konseling drngan menggunakn pengalaman yang dia miliki sebagai seorang ODHA dan menunjukkan realitas bagaimana kehidupan seorang ODHA sebenarnya.Dengan menunjukkan realitas yang ada, konselor KDS berharap pasien akan terbuka pikirannya, mendapatkan informasi yang benar tentang HIV/AIDS, dan tetap bersemangat menjalani hidup sebagai seorang ODHA.

Konseling dilakukan pra tes, paca tes dan konseling yang dilakukan sesuai dengan kebutuhan pasien. Dengan konseling yang dilakukan oleh konselor kepada pasien, diharapakan selain pasien mau mengubah pikiran dan persepsinya tentang HIV/AIDS, pasien akan membuka diri atau yang disebut dengan Self Disclosure. Melalui Self Disclosure, pasien akan menceritakan masalahmasalah apa saja yang dihadapi terkait dengan HIV/AIDS, sehingga konselor bisa membantu mencarikan solusi atas permasalahan yang sedang dihadapi oleh pasien.

\section{KESIMPULAN}

1. Strategi Komunikasi VCT Pra Tes HIV

Komunikasi Persuasif digunakan oleh konselor dengan tujuan untuk mempengaruhi ODHA agar mengubah persepsinya tentang HIV/AIDS dan melakukan Tes HIV serta kepada pasangan ODHA agar bersedia melakukan Tes HIV.

\section{Strategi Komunikasi VCT Pasca Tes HIV}

a. Komunikasi Persuasif digunakan oleh Konselor, dengan tujuan agar ODHA menerima status HIV nya, bersedia 
membuka diri dan tidak merasa sendiri ketika menghadapi masalah yang sedang dialami.

b. KIE dan komunikasi Persuasif digunakan oleh Konselordengan tujuan agar ODHA bersedia merubah perilakunya, yaitu menjadi disiplin dalam berobat dan bersedia meninggalkan perilaku yang beresiko.

KIE digunakan oleh Konselor kepada keluarga ODHA dengan tujuan agar terbentuk Support System yang berfungsi untuk melindungi ODHA dari stigma dan diskriminasi.

c. KIE juga digunakan oleh konselor ketika memberikan konseling kepada pasangan ODHA, dengan tujuan agar pasanganODHA bersedia menerima status HIV ODHA dan membentuk Support System, sehingga hal tersebut akan membuat ODHA termotivasi dan bersemangat menjalani hidup dengan penyakit yang dideritanya.

\section{SARAN}

\section{Kepada Pihak Rumah Sakit :}

Pendekatan secara personal dengan memberikan konseling kepada orang yang sedang mengalami sakit, merupakan salah satu alternatif yang bisa dicoba selain penggunaan obat-obatan secara terus menerus. Karena orang yang sakit bisanya butuh tempat untuk berbagi, butuh mendapat dukungan dan motivasi agar menjadi lebih bersemangat dalam menjalani hidup dengan penyakit yang dideritanya

\section{Kepada Masyarakat :}

ODHA tidak perlu ditakuti dan didiskriminasi, karena pada intinya ODHA sama dengan pasien yang menderita penyakit lainnya. Stigma dan diskriminasi kepada ODHAhanya akan menambah beban hidup merekayang pada akhirnya akan membuat ODHA tertutup dan berakibat pada sulitnya mendeteksi penyebaran HIV/AIDS.

\section{DAFTAR RUJUKAN}

\section{Dari Buku}

Bachtiar, W. 2006. Sosiologi Klasik. Bandung: PT. Remaja Rosdakarya

Bungin, B. 2001. Metode Penelitian Sosial, Format Kuantitatif dan
Kualitatif Surabaya : Airlangga U. P

Bungin, B. 2009. Sosiologi Komunikasi : Teori, Diskursus Teknologi Komunikasi Di

Masyarakat. Jakarta: Kencana Prenada Group

Browner, M.A.W dkk.1983. Rumah Sakit dalam Cahaya Ilmu Jiwa Jakarta :

PT Grafidian Jaya

De Vito, J. A.1996.Komunikasi Antar Manusia.Jakarta : Professional Books

Effendy, O. U.2003.Ilmu, Teori dan Filsafat Komunikasi. Bandung :PT. Citra Aditya Bhakti

George, R. and Douglas J. G.2004. Teori Sosiologi Modern. Jakarta : Prenada Media

Hasa, T.2002. Metodologi Penelitian Kualitatif : Tinjauan Teoritis dan Praktis.Malang: Lembaga Penelitian Universitas Islam Malang

Iriantara, Y.2004.Manajemen Strategis Public Relations.Jakarta : Ghalia Indonesia

Salusu, J.1996. Pengambilan Keputusan Stratejik Untuk Organisasi Publik dan Organisasi Non Profit. Jakarta : Grasindo

Lexy, J. M. 2007. Metode Penelitian Kualitatif. Bandung : PT REMAJA ROSDAKARYA

Liliweri, A.2007.Dasar-Dasar Komunikasi Kesehatan. Yogyakarta:Pustaka Pelajar

Lumenta, B. 1989. Pelayanan Medis Citra , Konflik dan Harapan.

Yogyakarta : Kanisius

Masmuh, A. 2010. Komunikasi Organisasi dalam Teori dan Praktek.Malang : UMM PRESS

Muhammad. A.2009.Komunikasi Organisasi. Yogyakarta : Bumi Aksara

Mulyana, D. 2005. Ilmu Komunikasi, Suatu Pengantar. Bandung : PT REMAJA ROSDAKARYA

Mulyana, D. 2005. Nuansa-Nuansa Komunikasi. Bandung. PT REMAJA ROSDAKARYA

Nina, S. 2009. Sosiologi Komunikasi.Bandung : Humaniora

Muzaham,F.1995. Sosiologi Kesehatan.Jakarta : UI Press

Peter, L. B. dan Thomas L. 1990. Tafsir Sosial Atas Kenyataan Jakarta : LP3ES

Rachmad K. Dwi Susilo. 2008. 20 Tokoh Sosiologi Modern. Yogyakarta : AR-Ruhz Media 
Sugiyono.2012. Memahami Penelitian Kualitatif. Bandung : CV Alfabeta

Silalahi, U. 2009. Metode Penelitian Sosial. Bandung : Rafika Aditama

Suyanto, B. 2010. Anatomi Dan Perkembangan Teori Sosial Yogyakarta Aditya Media

Sutaryo. 2005. Sosiologi Komunikasi.Yogyakarta: Arti Bumi Intaran

Dari Internet :

Definisi,Sejarah, Gejala, Cara Penularan dan Penyebaran HIV AIDS

hanifatunissa.wordpress.com. Diakses 1011-2012, pukul 21.00 wib
Orang yang Beresiko Tertular HIV AIDS.MakhlukSurga.BlogSpot.com Diakses 10-11-2012, pukul 21.15

Anti Stigma dan Diskriminasi Terhadap ODHA.dofan.wordpress.com

Diakses 10-11-2012, pukul 20.15

Cara Mencegah HIV Aids Secara Efektif.Carakata.blogspot.com Diakses 13-11-2012, pukul 19.11

Definisi VCT. Kpa.provsu.og. Diakses 13-112012, pukul 19.25 
80|l Kresna, Strategi Komunikasi Voluntary Counselin..... 